\title{
From the Editor of Sexuality and Disability: Is the Definition of Sexuality and Disability Changing to be More Inclusive or Are We Correcting a Bias of Exclusion?
}

\author{
Sigmund Hough ${ }^{1}$
}

Published online: 30 July 2015

(C) Springer Science+Business Media New York 2015

The journal of Sexuality and Disability remains a professional home for many and a place of professional rejuvenation for still more. If you are new to the journal, we give to you a "BIG WELCOME." Over decades of contribution to the literature on sexuality and disability, we have been a part of the growth and understanding. Now most importantly, we continue to be a part of change in how we look and examine the topic, the need, and the response in terms of best practice-evidence based approaches. With the intelligence, experience, motivation and commitment from our authors, readership and editorial board, and resources and guidance from the Springer Staff, our journal's mission is strong and meaningful.

The Impact Factor is 0.846 for 2014, comparable to 2013's 0.862, and higher than 2013 's 0.768 (with a trend from 0.8 to 0.9 ). Similarity, the number of citations has increased from 354 in 2013, to 369 in 2013, and now 490 in 2014.

The question of whether the definition of sexuality and disability is changing to be more inclusive or are we correcting a bias of exclusion is an important one. Knowing where we are going and how to get there, relies on the candid understanding of where we are coming from, how we started there, what has maintained us and what has allowed for change and growth. Also critical is the thoughtful and continued vigilant monitoring of who and what gets excluded and who or what gets included ... and why. These are just some of the exciting dynamics to keep in mind as we go forward together.

Sexuality and Disability continues to provide original impact articles addressing the mental health and medical aspects of sexuality in relation to rehabilitation, hospital, academic and community settings, publishing up-to-date articles, case studies, clinical practice reports, reviews, featured articles, historical articles, special grand rounds topics, brief research reports and survey data reports. Value benefit is provided to authors through worldwide electronic exposure and professional access, while readership gains from

Sigmund Hough

Sigmund_Hough@hms.harvard.edu

1100 Cummings Center, Suite 207, Beverly, MA 01915-6144, USA 
scholarly contributions to advance the field through research, best-practice and educational articles. The refined lens of individual contributions from the local and international community continues to deliver a wealth of information on the topic of sexuality and disability for the reader. Thank you for being a part of our professional community. 